\title{
Modeling of soil nitrification responses to temperature reveals thermodynamic differences between ammonia-oxidizing activity of archaea and bacteria
}

\author{
Anne E Taylor ${ }^{1}$, Andrew T Giguere ${ }^{1}$, Conor M Zoebelein ${ }^{2}$, David D Myrold ${ }^{1}$ \\ and Peter J Bottomley ${ }^{1,3}$ \\ ${ }^{1}$ Department of Crop and Soil Science, Oregon State University, Corvallis, OR, USA; ${ }^{2}$ Department of \\ Environmental Engineering, Oregon State University, Corvallis, OR, USA and ${ }^{3}$ Department of Microbiology, \\ Oregon State University, Corvallis, OR, USA
}

\begin{abstract}
Soil nitrification potential (NP) activities of ammonia-oxidizing archaea and bacteria (AOA and AOB, respectively) were evaluated across a temperature gradient $\left(4-42^{\circ} \mathrm{C}\right.$ ) imposed upon eight soils from four different sites in Oregon and modeled with both the macromolecular rate theory and the square root growth models to quantify the thermodynamic responses. There were significant differences in response by the dominant AOA and AOB contributing to the NPs. The optimal temperatures $\left(T_{\mathrm{opt}}\right)$ for AOA- and AOB-supported NPs were significantly different $(P<0.001)$, with AOA having $T_{\text {opt }}>12^{\circ} \mathrm{C}$ greater than $\mathrm{AOB}$. The change in heat capacity associated with the temperature dependence of nitrification $\left(\Delta C_{P}^{\ddagger}\right)$ was correlated with $T_{\text {opt }}$ across the eight soils, and the $\Delta C_{P}^{\ddagger}$ of AOB activity was significantly more negative than that of $A O A$ activity $(P<0.01)$. Model results predicted, and confirmatory experiments showed, a significantly lower minimum temperature $\left(T_{\min }\right)$ and different, albeit very similar, maximum temperature $\left(T_{\max }\right)$ values for $A O B$ than for AOA activity. The results also suggested that there may be different forms of AOA AMO that are active over different temperature ranges with different $T_{\min }$, but no evidence of multiple $T_{\min }$ values within the AOB. Fundamental differences in temperature-influenced properties of nitrification driven by $A O A$ and $A O B$ provides support for the idea that the biochemical processes associated with $\mathrm{NH}_{3}$ oxidation in AOA and AOB differ thermodynamically from each other, and that also might account for the difficulties encountered in attempting to model the response of nitrification to temperature change in soil environments.

The ISME Journal (2017) 11, 896-908; doi:10.1038/ismej.2016.179; published online 20 December 2016
\end{abstract}

\section{Introduction}

Both ammonia-oxidizing archaea (AOA) and bacteria (AOB) co-habit diverse soils. In some situations, AOA outnumber $\mathrm{AOB}$ by two to three orders of magnitude, and in other cases, their abundances are more similar (Leininger et al., 2006, Adair and Schwartz, 2008, Schauss et al., 2009, Taylor et al., 2012). Considerable debate has occurred about the relative contributions of $\mathrm{AOA}$ and $\mathrm{AOB}$ to soil nitrification, and the factors that may influence those contributions (Schleper, 2010, Hatzenpichler, 2012, Prosser and Nicol, 2012). There is direct and indirect evidence that factors such as increased $\mathrm{CO}_{2}, \mathrm{~N}$ concentration and form, $\mathrm{pH}$, and temperature differentially influence $\mathrm{AOA}$ and $\mathrm{AOB}$ contributions to

Correspondence: AE Taylor, Departments of Crop and Soil Science, Oregon State University, 3017 Ag Life Science Building, Corvallis, OR 97331, USA.

E-mail: anne.taylor@oregonstate.edu

Received 11 April 2016; revised 25 October 2016; accepted 4 November 2016; published online 20 December 2016 nitrification (Hu et al., 2015, Liu et al., 2015, Sun et al., 2015). For example, growth of pure cultures of AOB isolates is usually optimal $\leqslant 30^{\circ} \mathrm{C}$ (Jiang and Bakken, 1999), and one AOB, Nitrosomonas cryotolerans, can grow at $4-5^{\circ} \mathrm{C}$ (Jones et al., 1988). These observations corroborate several studies that showed the temperature optimum of soil nitrification is often $\leqslant 30^{\circ} \mathrm{C}$ (Malhi and McGill, 1982; Dalias et al., 2002; Avrahami et al., 2003; Fierer et al., 2003), and soil nitrification has been measured at temperatures as low as $2^{\circ} \mathrm{C}$ (Cookson et al., 2002).

However, a few reports have described nitrification in soils from western United States and Australia with temperature optima of $35-40{ }^{\circ} \mathrm{C}$ (Myers, 1975; Stark and Firestone, 1996). The isolation of the AOA Nitrososphaera gargensis and Nitrosocaldus yellowstonii from geothermal sources with temperature optima of 46 and $65-72^{\circ} \mathrm{C}$, respectively (de la Torre et al., 2008; Hatzenpichler et al., 2008), and the discovery of AOA soil isolates, Nitrosotalea devanaterra Nd1, 'Candidatus Nitrosocosmicus franklandus' and Nitrososphaera viennensis, growing optimally at $35-40{ }^{\circ} \mathrm{C}$ (Tourna et al., 
2011; Lehtovirta-Morley et al., 2014; LehtovirtaMorley et al., 2016), led us to speculate that AOA might be primarily responsible for soil nitrification $\geqslant 30^{\circ} \mathrm{C}$. In a field study, we previously observed increases of AOA numbers, and evidence of their activity, in cropped soils under late summer/early fall conditions when soil temperatures reached 30-35 ${ }^{\circ} \mathrm{C}$ (Taylor et al., 2012), and studies from a UK agricultural soil incubated at temperatures between 10 and $30^{\circ} \mathrm{C}$ showed that the thaumarchaeal composition (determined by analysis of the relative abundance of $16 \mathrm{~S}$ ribosomal RNA) shifted during incubation at 25 and $30^{\circ} \mathrm{C}$, whereas there was no change in the AOB community composition (Tourna et al., 2008; Offre et al., 2009). In contrast, AOA were enriched from Arctic soils incubated at $20^{\circ} \mathrm{C}$, and rates of nitrification were measured in three Arctic soils incubated at $15^{\circ} \mathrm{C}$, where AOB amoA numbers were below detection (Alves et al., 2013).

In previous studies, we showed that the relative contributions of AOB and AOA to nitrifying activity varied among four pairs of noncropped and cropped soils sampled throughout the state of Oregon (Taylor et al., 2013, 2015; Giguere et al., 2015). In this study, the AOA and $\mathrm{AOB}$ contributions to the nitrification potential (NP) of the above-mentioned soils were evaluated over a temperature range that they annually experience $\left(4-42^{\circ} \mathrm{C}\right)$. We hypothesized that $\mathrm{AOA}$ and $\mathrm{AOB}$ would exhibit different characteristic responses to temperature, and to quantify these differences we used two models: the square root growth model (SQRT) that has been used to relate soil respiratory and growth processes to temperature (Birgander et al., 2013; van Gestel et al., 2013), and the macromolecular rate theory model (MMRT) utilized by Schipper et al. (2014) to model the temperature response of a variety of microbial activities, including nitrification.

\section{Materials and methods}

Chemicals

Vanadium chloride, 1-octyne $\left(\mathrm{C}_{8}\right)$ and $\mathrm{NH}_{4} \mathrm{Cl}$ were obtained from Sigma-Aldrich (St Louis, MO, USA). Acetylene was obtained from Airgas (Radnor, PA, USA).

\section{Collection of soils}

In the spring of 2014, soil samples, representing different soil types from different climate regions of Oregon, were collected from cropped fields and noncropped locations at four locations (three replicates of each) at Oregon State University Agricultural Experimental Stations located in Corvallis, Pendleton, Madras and Klamath Falls, Oregon (Taylor et al., 2013; Giguere et al., 2015). Four to five soil samples were recovered to a depth of $10 \mathrm{~cm}$ from each replicate site via a random walk process. A composited sample was prepared for each replicate site and brought to the laboratory where they were sieved $<4.75 \mathrm{~mm}$. The soils were stored at $4^{\circ} \mathrm{C}$ before experimentation.

Response of soil NPs to temperature

NPs were determined on soil samples as described previously (Taylor et al., 2010b), except slurries were shaken at a range of temperatures $\left(4-42^{\circ} \mathrm{C}\right)$ in deionized water containing $1 \mathrm{mM} \mathrm{NH}_{4}^{+}$. Some NP treatments included octyne $(4 \mu \mathrm{M})$ to distinguish between AOA and AOB activities, using a procedure described by Taylor et al. (2013). AOA are octyne resistant, and AOB are octyne sensitive (total nitrification - nitrification by octyne-resistant AOA). NP controls were comprised of soil suspensions to which acetylene was added $(10 \mu \mathrm{M})$ to evaluate the possibility of acetylene-resistant heterotrophic nitrification, and also to assess the significance of $\mathrm{NO}_{3}^{-}$ consumption due to assimilation or denitrification. Each treatment had three replicates. Accumulation of $\mathrm{NO}_{2}^{-}+\mathrm{NO}_{3}^{-}$was monitored over a 3-day interval in incubations performed at 4,10 and $16^{\circ} \mathrm{C}$, whereas 1 day was sufficient for incubations at higher temperatures. The accumulation of $\mathrm{NO}_{2}^{-}+\mathrm{NO}_{3}^{-}$in the NPs was considered to be the rate of nitrification. $\mathrm{NO}_{2}^{-}$accumulated to various fractions of the total $\mathrm{NO}_{2}^{-}+\mathrm{NO}_{3}^{-}$in actively nitrifying soil slurries over the temperature range, and generally increased as temperature increased but did not change the overall rate of $\mathrm{NO}_{2}^{-}+\mathrm{NO}_{3}^{-}$accumulation. The accumulation of $\mathrm{NO}_{2}^{-}+\mathrm{NO}_{3}^{-}$in the 1- or 3-day NPs was linear at all temperatures, indicating that there was no change in the nitrifier abundance or adaptation/recovery of NP activity over the course of the NP assays. There was no significant $\mathrm{NO}_{3}^{-}$consumption or production in plus acetylene controls (data not shown), indicating all $\mathrm{NO}_{2}^{-}+\mathrm{NO}_{3}^{-}$accumulation was likely due to $\mathrm{NH}_{4}^{+-}$ dependent nitrification, and that alternate sinks for $\mathrm{NO}_{2}^{-}$or $\mathrm{NO}_{3}^{-}$were not significant under NP conditions.

Modeling of the nitrification response to temperature Each replicate of the NP temperature response data was modeled using two methods. The first was the SQRT developed by Ratkowsky et al. (1983) to describe bacterial growth response to temperature, but has been used more recently to describe soil respiratory and growth processes to temperature (Birgander et al., 2013; van Gestel et al., 2013). Here it was used to model the NP response to temperature:

$\left.\sqrt{\text { Bacterial growth }}=a\left(T-T_{\min }\right)\left(1-e^{b(T-T \max }\right)\right)$

Four unknown parameters were fit to this model in MATLAB (The MathWorks Inc., Natwick, MA, USA): (i) ' $a$ ' is a parameter associated with the temperature response of activity at temperatures below the temperature at which the highest nitrification rates 
were obtained ( $T_{\text {opt }}$ ); (ii) $T_{\min }$ represents a theoretical constant describing the $x$-intercept, and is referred to as the apparent minimum temperature at which activity is measured; (iii) ' $b$ ' describes the decrease in nitrifying activity above $T_{\text {opt }}$; and (iv) $T_{\max }$ represents the maximum temperature where activity may be detected. $T_{\text {opt }}$ is described by the Equation

$$
-a\left(\left(b\left(T-T_{\min }\right)+1\right) e^{\left(b\left(T-T_{\max }\right)\right)}-1\right)=0
$$

The second model used was MMRT utilized by Schipper et al. (2014) to model the temperature response of a variety of microbial activities, including nitrification, and is described by the Equation

$$
\begin{aligned}
\ln (k)= & \ln \left(\frac{k_{\mathrm{B}} T}{h}\right)-\frac{\Delta H_{T_{\mathrm{o}}}^{\ddagger}+\Delta C_{P}^{\ddagger}\left(T-T_{\mathrm{o}}\right)}{R T} \\
& +\frac{\Delta S_{T_{\mathrm{o}}}^{\ddagger}+\Delta C_{P}^{\ddagger}\left(\ln T-\ln T_{\mathrm{o}}\right)}{R}
\end{aligned}
$$

where $k$ is the rate constant, $T_{\text {naught }}\left(T_{\mathrm{o}}\right)$ is the reference temperature at which the fitting process is initiated, $k_{\mathrm{B}}$ is Boltzmann's constant, $h$ is Planck's constant and $R$ is the universal gas constant (8.314 $\mathrm{J} \mathrm{K}^{-1} \mathrm{~mol}^{-1}$ ). Three unknown parameters were fit to the model using SigmaPlot (Systat Software, San Jose, CA, USA): (i) the change of enthalpy of AOA or AOB supported nitrification $\left(\Delta H_{T_{0}}^{\ddagger}\right)$, (ii) the change of entropy of the AOA or AOB supported nitrification $\left(\Delta S_{T_{0}}^{\dagger}\right)$, and (iii) the change in heat capacity associated with temperature dependence of $\mathrm{NO}_{2}^{-}+\mathrm{NO}_{3}^{-}$accumulation attributed to AOA or AOB $\left(\Delta C_{P}^{\ddagger}\right)$. The temperature for optimum activity $T_{\text {opt }}$ is described by:

$T_{\mathrm{opt}}=\frac{\Delta H_{T_{\mathrm{o}}}^{\ddagger}+\Delta C_{P}^{\ddagger} T_{\mathrm{o}}}{-\Delta C_{P}^{\ddagger}-R}$

The temperature where the AOA- or AOB-supported $\mathrm{NO}_{2}^{-}+\mathrm{NO}_{3}^{-}$accumulation rate shows maximum sensitivity to changes in temperature $\left(T_{\mathrm{s} \_ \text {max }}\right)$ is described by:

$$
T_{S_{\max }} \frac{T_{\mathrm{opt}}}{1+\sqrt{\frac{k}{\Delta C_{P}^{\ddagger}}}}
$$

From the modeling activities, we obtained information that predicted there were different temperature responses of AOA- and AOB-driven activities. As a consequence, a series of experiments were conducted to (i) gain further insights into how well the recovery of acetylene-inactivated $\mathrm{NO}_{2}^{-}+\mathrm{NO}_{3}^{-}$ production activity in both AOA- and AOB (biosynthetic competence) matched $\mathrm{NO}_{2}^{-}+\mathrm{NO}_{3}^{-}$production activity across the temperature range, (ii) confirm the predicted $T_{\min }$ and $T_{\max }$ of AOA and AOB activity, and (iii) determine whether $T_{\text {s_max }}$ values reflected simply a thermodynamic response of preexisting activity potential, or whether they were influenced by the recruitment/activation of nitrifying activity of subpopulations with different temperature profiles. This series of experiments was conducted in Pendleton noncropped soils where both AOA and AOB consistently demonstrated their highest rates of $\mathrm{NO}_{2}^{-}+\mathrm{NO}_{3}^{-}$production activity.

\section{The effect of temperature on acetylene inactivation of soil slurries}

(i) Does biosynthetic competence match $\mathrm{NO}_{2}^{-}+\mathrm{NO}_{3}^{-}$ production activity in AOA and AOB? The ability of acetylene to irreversibly denature $\mathrm{NH}_{3}$ monooxygenase (AMO) depends upon the enzyme being potentially active and capable of using acetylene as a substrate under the experimental conditions; recovery of AMO activity is dependent upon the ability to carry out de novo protein synthesis under the same conditions. Therefore, we used the recovery of nitrification potential (RNP) assay as a surrogate to assess the protein synthesis (biosynthetic) potential of the $\mathrm{AOB}$ and $\mathrm{AOA}$ at a range of temperatures $\left(10,16,23,30\right.$ or $\left.37^{\circ} \mathrm{C}\right)$ in Pendleton noncropped soil. Details of the RNP assay have been described previously (Taylor et al., 2010b). Soils were preincubated at field capacity for 2-3 days at specific temperatures of $10,16,23$ or $30^{\circ} \mathrm{C}$, or for a shorter duration (18 h) at $37^{\circ} \mathrm{C}$. Then, the soils were slurried in deionized water containing $1 \mathrm{mM} \mathrm{NH}_{4}^{+}$, exposed to acetylene $\left(10 \mu \mathrm{M} \mathrm{C}_{\mathrm{aq}}\right)$ for $6 \mathrm{~h}$ at each of the specific temperatures, after which acetylene was removed by evacuation under vacuum, and RNP determined plus and minus bacterial protein synthesis inhibitors $\left(\mathrm{RNP}_{\mathrm{ab}}, 800 \mu \mathrm{g} \mathrm{ml}^{-1}\right.$ kanamycin plus $400 \mu \mathrm{g} \mathrm{ml}^{-1}$ spectinomycin) at the specific inactivation temperatures. At $10^{\circ} \mathrm{C}$, soil was allowed to recover activity for $90 \mathrm{~h}$, whereas the magnitude of recovery at other temperatures was determined after 48-72 h. Controls included (a) no alkyne amendment, (b) plus acetylene $\left(10 \mu \mathrm{M} \mathrm{C}_{\mathrm{aq}}\right)$ and (c) plus octyne $\left(4 \mu \mathrm{M} \mathrm{C}_{\mathrm{aq}}\right)$ treatments to establish the AOA- and AOBdependent activities at each temperature.

(ii) Effect of temperature on the magnitude of acetylene inactivation of optimal nitrification activity to experimentally determine $T_{\min }$ and $T_{\max }$. Noncropped Pendleton soil was preincubated at temperatures ranging from 4 to $42^{\circ} \mathrm{C}$ as described above. Soils were slurried in distilled $\mathrm{H}_{2} \mathrm{O}$ containing $1 \mathrm{mM} \mathrm{NH}_{4}^{+}$and exposed to acetylene $\left(10 \mu \mathrm{M} \mathrm{C}_{\mathrm{aq}}\right)$ for $6 \mathrm{~h}$ at each specific preincubation temperature. Then, acetylene was removed by vacuum, and soil slurries were incubated plus and minus $4 \mu \mathrm{M}\left(\mathrm{C}_{\mathrm{aq}}\right)$ octyne with shaking at 16 or $37^{\circ} \mathrm{C}$ (the optimal temperatures for AOB or AOA activity in this soil, respectively, see Figure 1). Controls included no alkyne amendment, plus acetylene $\left(10 \mu \mathrm{M} \mathrm{C}_{\mathrm{aq}}\right)$ and plus octyne $\left(4 \mu \mathrm{M} \mathrm{C}_{\mathrm{aq}}\right)$ treatments to evaluate the effect of the temperature inactivation step on activity at the optimal temperatures. Maximum $\mathrm{RNP}_{\mathrm{AOA}}$ at $37^{\circ} \mathrm{C}$ in this soil normally occurred between 24 and $48 \mathrm{~h}$ after acetylene removal, and maximum $\mathrm{RNP}_{\mathrm{AOB}}$ 
at $16{ }^{\circ} \mathrm{C}$ occurred between 48 and $72 \mathrm{~h}$ after acetylene removal. Accumulation of $\mathrm{NO}_{2}^{-}+\mathrm{NO}_{3}^{-}$after $\leqslant 12 \mathrm{~h}$ of incubation was considered to be residual $\mathrm{NH}_{3}-$ oxidizing activity that had escaped acetylene inactivation. The octyne-resistant residual activity was considered to be residual AOA activity, whereas residual AOB activity was calculated as the difference between the plus and minus octyne treatments.
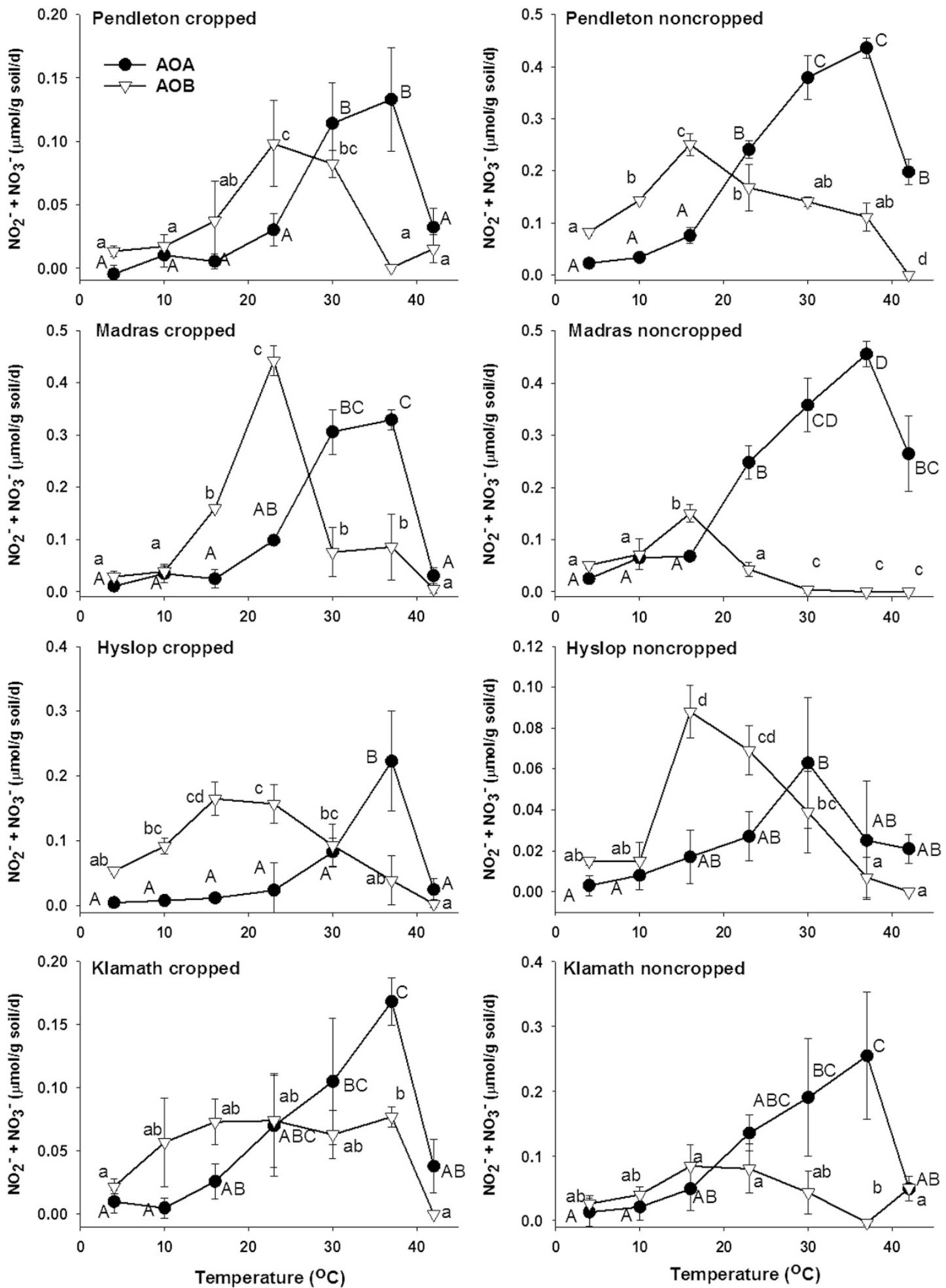

Figure 1 Nitrification potential response of AOA and AOB in cropped and noncropped soils to a range of temperatures (4-42 ${ }^{\circ} \mathrm{C}$ ). Symbols with error bars represent the s.d. of the average of three replicate measurements. Upper case letters indicate significant differences $(P<0.05)$ in rates of nitrification by AOA at each temperature. Lower case letters indicate significant differences $(P<0.05)$ between rates of nitrification by AOB at each temperature. Temperatures that have letters in common were not significantly different. 
To confirm that $6 \mathrm{~h}$ of incubation in the presence of acetylene was sufficient to completely inhibit all $\mathrm{NH}_{3}$-oxidizing activity occurring at temperatures of 10,23 and $30^{\circ} \mathrm{C}$, a longer exposure time $(10 \mathrm{~h})$ was evaluated. There was no significant difference $(P>0.1)$ between the residual activity after the two periods of acetylene inactivation.

\section{Statistical analysis}

To determine the significant differences $(P<0.05)$ in AOA or AOB NP activities over the $4-42^{\circ} \mathrm{C}$ range, analysis of variance (ANOVA) tests with the TukeyKramer adjustment were performed using the three replicates in Statgraphics Version 17.1.06 (Statpoint Technologies, Warrenton, VA, USA) for all pair-wise comparisons among temperatures within each soil. With the sites as replicates, ANOVA using the default Type III Sum of Squares was performed in Statgraphics on the average of the mean of each of the model coefficients to determine the statistical significance of each factor. ANOVA using the HolmSidak method was used for pair-wise comparisons in SigmaPlot (Systat Software, San Jose, CA, USA) to determine whether there were significant differences in AOA or AOB activity after acetylene treatment.

\section{Results}

$A O A$ and $A O B$ contributions to $\mathrm{NO}_{2}^{-}+\mathrm{NO}_{3}^{-}$production over a temperature profile

The soil AOA and AOB contributions to the NPs of four pairs of adjacent cropped and noncropped soils were evaluated over a temperature range of $4-42^{\circ} \mathrm{C}$ using the octyne method to discriminate between AOA and AOB activities (Figure 1). Regardless of soil origin or cropping history, AOA consistently expressed their maximum NP rates between 30 and $37^{\circ} \mathrm{C}$ where they contributed virtually all of the NP. In contrast, $\mathrm{AOB}$ expressed their maximum NP rates at either 16 or $23^{\circ} \mathrm{C}$, contributing most of the total NP in cropped and noncropped soils. The experiments were repeated with soils collected from the same sites in the summer and fall of 2014 and the same trends were observed (data not shown).

To further quantify the differences in temperature response of AOA and AOB driven activities, two complementary models that have been previously used to describe the response of soil processes to temperature, MMRT and SQRT, were applied to the data (Figure 2; Supplementary Tables 1 and 2). Based on estimates of least squared error, the SQRT model fit the temperature response better than the MMRT model $(0.03 \pm 0.02$ and $1.77 \pm 1.40$ for SQRT and MMRT); however, there was not a significant difference in how well each model fit either the AOA or AOB temperature response $(P>0.2)$. Conversely, there was no difference between the SQRT and MMRT models on how well a regression of the model outcome approximated the experimental data; the models yielded coefficients of determination $\left(R^{2}\right)$ with an average of $0.75 \pm 0.13$ for MMRT and $0.77 \pm 0.15$ for SQRT models. In addition, there was no significant difference of any of the MMRT or SQRT model parameters between cropped and noncropped soils $(P>0.05)$.

When the AOA and AOB activity responses to temperature were compared, several model parameters were highly significantly different (Figure 3a). Both models identified $T_{\text {opt }}$ values (the optimal temperature at which activity is achieved) for AOA that were significantly greater than estimates of $T_{\text {opt }}$ for AOB $\left(P<0.000\right.$, Figure 3a), with the $T_{\text {opt }}$ derived from the SQRT model being significantly greater $\left(4.7 \pm 2.6^{\circ} \mathrm{C}\right)$ than that derived from the MMRT model $(P<0.000$, Supplementary Tables 1 and 2). The SQRT model estimated a $T_{\text {opt }}$ for AOA activity that was $12.8 \pm 4.4^{\circ} \mathrm{C}$ higher than that of $\mathrm{AOB}$ activity, and the $T_{\text {opt }}$ for AOA activity estimated by the MMRT model was $13.1 \pm 6.3^{\circ} \mathrm{C}$ higher than that of AOB.

The SQRT model generated a theoretical apparent minimum temperature of activity $\left(T_{\min }\right)$ for AOB that was significantly lower than that of AOA $(-8.8 \pm 5.3$ and $1.4 \pm 3.5^{\circ} \mathrm{C}$ for $\mathrm{AOB}$ and $\mathrm{AOA}$, respectively, $P<0.001$, Figure 3a). In addition, SQRT yielded a maximum temperature of activity, $T_{\max }$, for AOA that was significantly greater than that of AOB $(43.5 \pm 1.1$ and $\left.39.7 \pm 3.7^{\circ} \mathrm{C}, P<0.01\right)$. The temperature interval between $T_{\mathrm{opt}}$ and $T_{\max }\left(T_{\text {max-opt }}\right)$ was significantly greater for $\mathrm{AOB}$ than $\mathrm{AOA}(14.9 \pm 1.5$ and $5.9 \pm$ $2.6^{\circ} \mathrm{C}, P<0.000$ ), which was in agreement with the significant difference in the $b$ parameter (Supplementary Tables 1 and 2, $P<0.01$ ) that describes the much steeper decline in AOA activity above $T_{\text {opt }}$ compared with AOB. The MMRT model yielded a significant difference in the temperature at which the rate of nitrification showed maximum sensitivity to changes in temperature ( $T_{\mathrm{s} \text { max }}$, $P<0.000)$ between AOA and AOB activity $\left(20.9 \pm 3.0\right.$ and $11.1 \pm 2.4{ }^{\circ} \mathrm{C}$ for $\mathrm{AO} A$ and $\left.\mathrm{AOB}\right)$, and also in the heat capacity term $\Delta C_{P}^{\mp}$ (Supplementary Tables 1 and 2, $P<0.01$ ).

The curvature of the $\ln ($ rate) vs temperature plots of both AOA and AOB activities (Figures 2a-h) indicated that enthalpy and entropy $\left(\Delta H_{T 0}^{\ddagger}\right.$ and $\Delta S_{T 0}^{\ddagger}$, respectively) of the overall nitrification processes were temperature-dependent (Equation (3)), and the significant difference in $\Delta C_{P}^{\ddagger}$ pointed to potential differences in thermodynamic properties of AOA and AOB. A large negative $\Delta C_{P}^{\ddagger}$ of an enzyme reaction is associated with a lower $T_{\text {opt }}$ (Hobbs et al., 2013; Schipper et al., 2014). When the relationship between the response of $T_{\text {opt }}$ and $\Delta C_{P}^{\ddagger}$ of soil AOA and AOB activities was compared (Figure 3b), larger negative $\Delta C_{P}^{\ddagger}$ values correlated with lower $T_{\mathrm{opt}}$ across the spectrum of soils $\left(R^{2}=0.6201\right) ;$ and there was a clear trend for the $\Delta C_{P}^{\ddagger}$ of soil AOB-driven activity to be more 

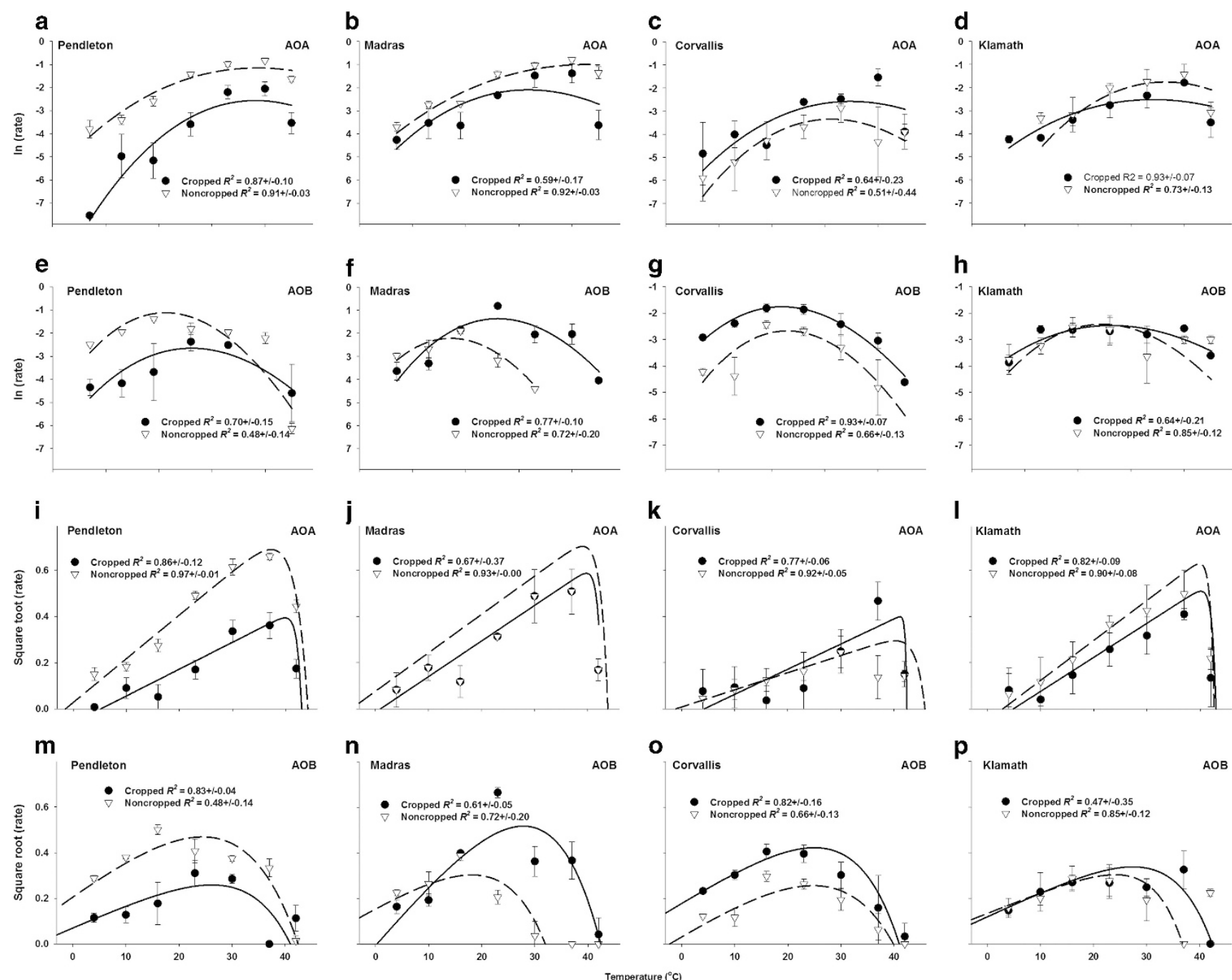

Figure 2 The fit of the MMRT (a-h) and SQRT (i-p) models to rates of $\mathrm{NO}_{2}^{-}+\mathrm{NO}_{3}^{-}$production by AOA and AOB in cropped (solid lines) and noncropped (broken lines) using the average of the model fit from each replicate. Symbols with error bars represent the s.d. of the average of the experimental data.

negative than of soil AOA-driven activity, implying differences in the thermodynamic properties of $\mathrm{NO}_{2}^{-}+\mathrm{NO}_{3}^{-}$production supported by the two groups of nitrifiers.

Experimental validation of insights into $A O A$ and $A O B$ activity differences gained from modeling of temperature-influenced parameters

A series of experiments were conducted to gain further insights into (i) protein biosynthetic competence of AOA and AOB across a temperature profile, (ii) how the predicted cardinal values of $T_{\min }$ and $T_{\max }$ reflect AOA and AOB activity, and (iii) how properties of $T_{\mathrm{s}_{\text {max }}}$ of AOA and AOB activity might be influenced by recruitment of AMO activity exhibiting different temperature profiles. These experiments were carried out in Pendleton noncropped soils because the high rates of both AOA and AOB activities expressed in this soil allowed for the execution of these detailed experiments.

Evaluation of protein biosynthetic potential in soil across a temperature profile. Using the RNP assay as a surrogate to assess protein synthesizing potential of AOA and AOB, the NP and RNP were compared across the temperature range in Pendleton noncropped soil (Figure 4). AOA demonstrated RNP $\left(\mathrm{RNP}_{\mathrm{AOA}}\right)$ at $10-37^{\circ} \mathrm{C}$, illustrating their effective protein synthesis potential at temperatures where significant nitrifying activity occurred (Figure 4a). However, at $37^{\circ} \mathrm{C}, \mathrm{RNP}_{\mathrm{AOA}}$ was significantly less than the $\mathrm{NP}_{\mathrm{AOA}}$ and $\mathrm{RNP}_{\mathrm{AOA}}$ did not occur at all at $42^{\circ} \mathrm{C}$, suggesting that high temperatures that support short-term rates of $\mathrm{NO}_{2}^{-}+\mathrm{NO}_{3}^{-}$ producing activity might not necessarily support biosynthetic potential and growth of all AOA population members. In contrast, AOB demonstrated $\mathrm{RNP}_{\mathrm{AOB}}$ 
902
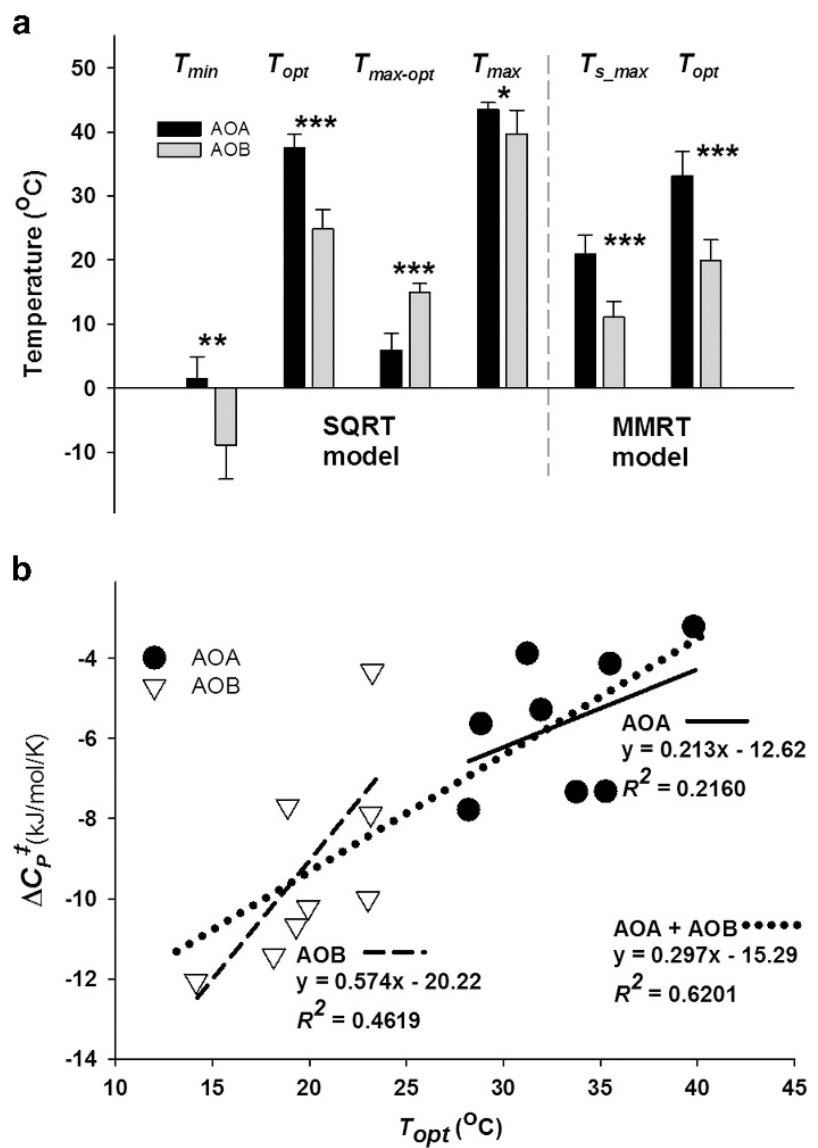

Figure 3 Significant outcomes from modeling the NP response to temperature in eight Oregon soils. (a) SQRT and MMRT model parameters that had significantly different values for $\mathrm{NO}_{2}^{-}+\mathrm{NO}_{3}^{-}$ production by soil AOA and AOB. The pairs of bars represent the average of the mean AOA or AOB value of a given parameter, and error bars represent the s.d. The asterisks assign the level of significance to each pair of bars $\left({ }^{*} P<0.01, \quad{ }^{*} P<0.001\right.$, ${ }^{* * *} P<0.0001$ ). (b) Comparison of the $\Delta C_{P}^{\ddagger}-T_{\text {opt }}-$ relationships of AOA and AOB in soil. Symbols represent the values for individual soils. The dotted regression line demonstrates the $\Delta C_{P}^{\ddagger}-T_{\mathrm{opt}^{-}}$ relationship for all AOA and $\mathrm{AOB}$ values across the entire temperature range. The solid and dashed regression lines are for the AOA and AOB $\Delta C_{P}^{\ddagger}-T_{\text {opt }}$ relationship, respectively.

only at 16, 23 and $30^{\circ} \mathrm{C}$ (Figure 4b) despite expressing substantial $\mathrm{NO}_{2}^{-}+\mathrm{NO}_{3}^{-}$producing activity over a wider temperature range $\left(4-37^{\circ} \mathrm{C}\right)$, suggesting a much narrower temperature range of protein synthesis and growth potential than for $\mathrm{NO}_{2}^{-}+\mathrm{NO}_{3}^{-}$producing activity per se.

Experimental validation of $T_{\min }$ and $T_{\max }$, and evidence for different and overlapping contributions to soil nitrification by different groups of ammonia oxidizers. We considered the possibility that subgroups of AOA and AOB might occupy different temperature niches within the overall range of temperatures and would possess different $T_{\min }$ and $T_{\max }$. It is known that acetylene is an irreversible inactivator of $\mathrm{AMO}$ of both $\mathrm{AOA}$ and $\mathrm{AOB}$ during active substrate turnover (Hyman and Wood, 1985; Taylor et al., 2013; Vajrala et al., 2014), and that de novo protein synthesis is required for activity to resume. Our hypothesis was that if the AMO of AOA or AOB are not actively turning over substrate at specific temperatures, they should not be inactivated by acetylene. We also hypothesized that we would observe heat inactivation of $\mathrm{NO}_{2}^{-}+\mathrm{NO}_{3}^{-}$accumulating activity above their modeled $T_{\max }$. To evaluate these hypotheses, Pendleton noncropped soil was inactivated with acetylene at a range of temperatures from 4 to $46^{\circ} \mathrm{C}$, and the residual activities after acetylene exposure measured at $16^{\circ} \mathrm{C}$ (temperature of optimal AOB activity) and $37^{\circ} \mathrm{C}$ (temperature of optimal AOA activity).

The SQRT model predicted $T_{\max }$ of 44.2 and $42.4{ }^{\circ} \mathrm{C}$ for AOA and AOB, respectively, in Pendleton noncropped soil. To determine whether both AOA and AOB were capable of oxidizing $\mathrm{NH}_{3}$ or enzyme turnover at temperatures $>40{ }^{\circ} \mathrm{C}$, Pendleton noncropped soil was exposed to acetylene at 42,44 or $46^{\circ} \mathrm{C}$, and then transferred to 16 or $37^{\circ} \mathrm{C}$. After acetylene exposure of soil at $42^{\circ} \mathrm{C}$, there was no residual AOA- or AOB-driven activity significantly greater than zero over $12 \mathrm{~h}$ of incubation (Figures 4C and d). These data indicate that both AOA and AOB were capable of expressing sufficient AMO activity for acetylene to inactivate all $\mathrm{NO}_{2}^{-}+\mathrm{NO}_{3}^{-}$production activity, even though AOB-driven $\mathrm{NO}_{2}^{-}+\mathrm{NO}_{3}^{-}$accumulation could not be measured at $42^{\circ} \mathrm{C}$ over $24 \mathrm{~h}$. Both AOA and AOB retained all their $\mathrm{NO}_{2}^{-}+\mathrm{NO}_{3}^{-}$ production activities when returned to 16 or $37^{\circ} \mathrm{C}$, respectively, in non-acetylene exposed controls after incubation at $42{ }^{\circ} \mathrm{C}$, demonstrating there was no irreversible heat inactivation of cellular functions at this temperature. After acetylene exposure at $44^{\circ} \mathrm{C}$, there was no significant residual post-acetylene exposure AOA activity, again indicating that AOA expressed sufficient AMO turnover at $44^{\circ} \mathrm{C}$ for acetylene to inactivate all activity, but in the nonacetylene controls all activity was retained. In contrast, there was no residual AOB activity in either the non-acetylene or acetylene treatments exposed to $44^{\circ} \mathrm{C}$, suggesting that the upper limit of AOB thermal stability had been exceeded. Incubations at $46^{\circ} \mathrm{C}$ heat-inactivated both $\mathrm{AOA}$ and $\mathrm{AOB}$ activity regardless of acetylene treatment. Despite the close similarity of $T_{\max }$ values for AOA and AOB activities, the outcome of the experiment confirmed the model prediction.

The SQRT model also predicted significant differences in $T_{\min }$ of AOA and AOB, and when acetylene inactivation was carried out at $4{ }^{\circ} \mathrm{C}$ and the soil moved to $37^{\circ} \mathrm{C}$, all of the octyne-resistant AOA activity was immediately expressed, indicating that none of the AOA AMO activity was actively turning over substrate during acetylene exposure at $4{ }^{\circ} \mathrm{C}$, and that $T_{\min }$ of the active soil AOA must be $>4^{\circ} \mathrm{C}$. In contrast, there was no residual AOB activity significantly greater than zero at $16{ }^{\circ} \mathrm{C}$ after acetylene exposure at $4{ }^{\circ} \mathrm{C}$ (Figure $4 \mathrm{~d}$ ) verifying the model 

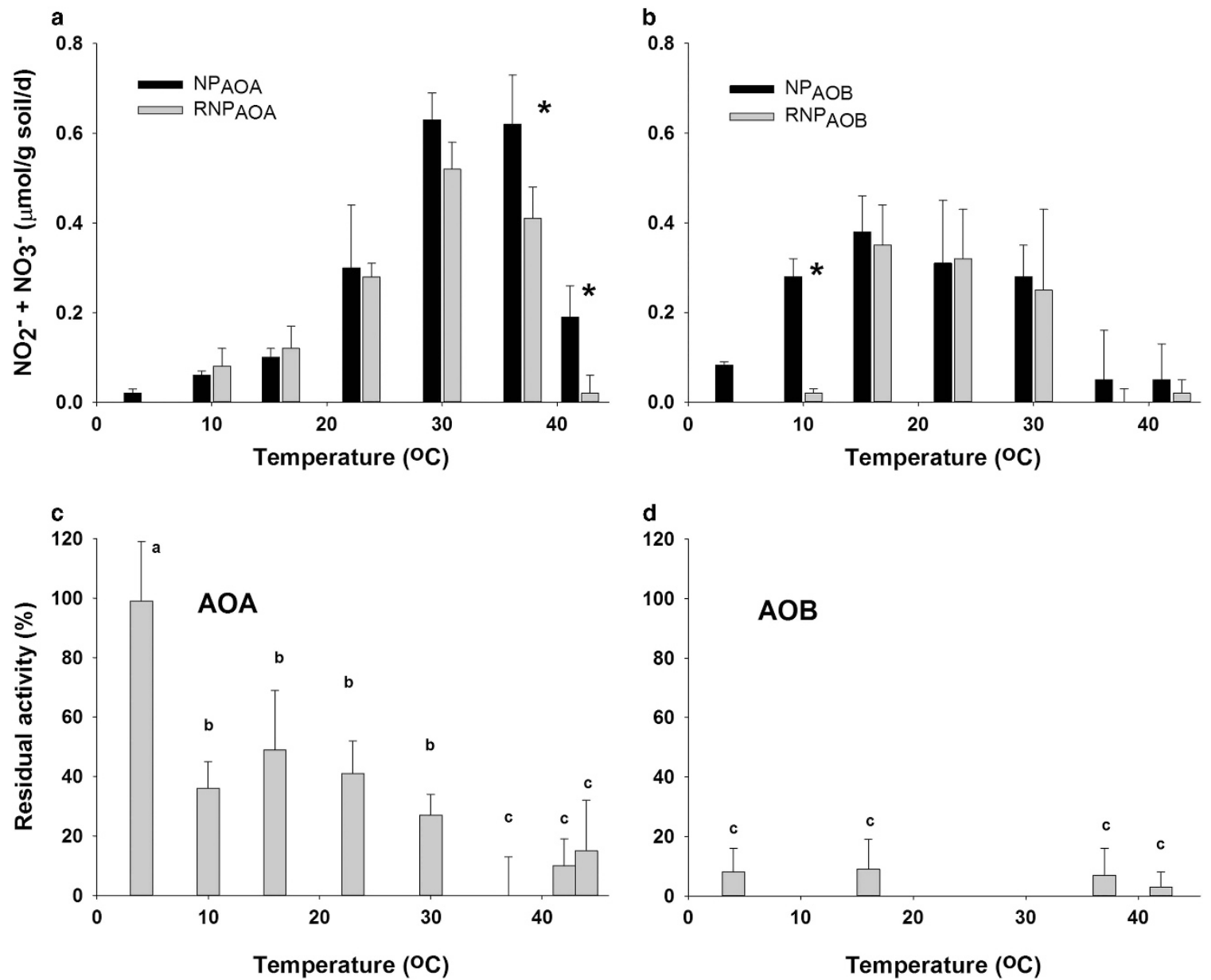

Figure 4 The effect of acetylene exposure on AOA and AOB in Pendleton noncropped soil. Evaluation of biosynthesis potential (RNP) of AOA (a) or AOB (b) in comparison with potential nitrification activity (NP) over a range of temperatures in Pendleton noncropped soil. Soils were inactivated and activity recovered at the same temperature. Error bars represent the s.d. of three replicates. The asterisks (*) represent the NP and RNP that were significantly different at the same temperature $(P>0.05)$. The effect of acetylene on the residual $T_{\text {opt }}$ activity of AOA at $37^{\circ} \mathrm{C}(\mathbf{c})$ or AOB at $16^{\circ} \mathrm{C}(\mathbf{d})$. Soil was acetylene-inactivated at 4 through $46^{\circ} \mathrm{C}$ for $6 \mathrm{~h}$, degassed, and transferred to $37^{\circ} \mathrm{C}$ for measurement of AOA residual activity, or $16{ }^{\circ} \mathrm{C}$ for measurement of AOB residual activity. Residual activity measured between 0 and $12 \mathrm{~h}$ was considered to be due to AMO that was not acetylene-inactivated. Error bars represent the s.d. of three replicates. Lower case letters indicate significant differences between residual activities $(P<0.01)$. Bars with the same letter are not significantly different.

prediction that the soil AOB were active at $4{ }^{\circ} \mathrm{C}$ and possess a lower $T_{\min }$ than the soil AOA.

When acetylene inactivation of Pendleton noncropped soil was performed at $10^{\circ} \mathrm{C}$, however, and the slurries subsequently transferred to $37^{\circ} \mathrm{C}$, only a fraction of the non-acetylene exposed octyne-resistant activity $(27-49 \%)$ was immediately expressed, indicating that a fraction $(51-63 \%)$ of the AOA potential activity had become active at the lower incubation temperatures between 10 and $30{ }^{\circ} \mathrm{C}$ and inactivated by acetylene. Longer exposures to acetylene at $\leqslant 30^{\circ} \mathrm{C}$ did not increase the fraction of activity that was inactivated. The response to acetylene inactivation across the temperature range suggested that there may be different types of AMO within the AOA population with one response type having a $T_{\min }$ between 4 and $10^{\circ} \mathrm{C}$, and another AMO response type with a $T_{\min }$ that must be higher than $30^{\circ} \mathrm{C}$. Evidence of different temperature responsive AOA
AMO activities could indicate that $T_{s_{\max }}$ of AOA might be explained by different AOA AMO types with different $T_{\min }$ values active across different ranges of temperature.

In the case of $\mathrm{AOB}$, there was no significant residual nitrifying activity at $16^{\circ} \mathrm{C}$ after acetylene exposure at any temperature, indicating that the soil AOB expressed sufficient AMO activity across the whole temperature range to be inactivated by acetylene. This indicates that the $\mathrm{AOB}$ actively contributing to the measured $\mathrm{NO}_{2}^{-}+\mathrm{NO}_{3}^{-}$production in the Pendleton noncropped soil may have AMO possessing the same temperature response profile, and that $T_{\mathrm{s}_{\max }}$ describes the thermodynamic response of AOB AMO to temperature increase.

\section{Discussion}

We have measured the temperature response of the AOA and AOB actively contributing to $\mathrm{NO}_{2}^{-}+\mathrm{NO}_{3}^{-}$ 
production in eight Oregon soils, and collected data demonstrating that soil $\mathrm{AOA}$ and $\mathrm{AOB}$ possess different temperature-dependent characteristics and contribute differentially to soil nitrification over a range of temperature. The temperature responses were evaluated in well-aerated soil slurry NPs containing saturating $\mathrm{NH}_{4}^{+}$. Although we readily concede that our results might not necessarily extrapolate to all soils, and in situ whole soil nitrification, nonetheless, several interesting points have arisen from this work that are worthy of comment and further study. For example, because it appears that AOA and AOB AMO possess different responses to temperature, it is perhaps not surprising that it has been challenging to model the response of soil nitrification to temperature (Stark, 1996), and for Schipper et al. (2014) to determine the parameters $T_{\text {opt }}$ and $\Delta C_{P}^{\ddagger}$ when the temperature range of their data set only extended from 5 to $20^{\circ} \mathrm{C}-$ a range below the $T_{\text {opt }}$ of AOA in the soils used in our study. Similarly, a trait-based modeling approach to nitrification was limited by both the lack of data obtained with AOA and AOB laboratory isolates, and a comprehensive data set with which to test the model (Bouskill et al., 2012). By distinguishing between AOA and AOB contributions to soil NPs with the octyne method over a range of temperatures, and then evaluating those data using models with either empirical or thermodynamic underpinnings, we were able to parameterize some of the characteristics of nitrification driven by $\mathrm{AOA}$ and $\mathrm{AOB}$, respectively. Our results agree with, and in part explain what has previously been observed, but also contribute new insights into how AOA and AOB may contribute differentially to nitrification in soils. The discovery of Nitrospira capable of complete nitrification (comammox) potentially adds further complexity to the interpretation of the $\mathrm{AOA}$ and $\mathrm{AOB}$ contributions in soil (Daims et al., 2015; van Kessel et al., 2015). Nonetheless, limited data imply that comammox is highly sensitive to octyne (Daims, personal communication) and, therefore, should not interfere with any conclusions drawn about octyneresistant AOA activity. How important the contributions of comammox to nitrification are in soils will remain unknown until tools to discriminate between comammox activity and that of AOA and AOB have been developed.

\section{Significance of the model results}

The SQRT and MMRT models were in agreement that $T_{\text {opt }}$ for AOA activity was significantly greater than that of AOB. This observation was true for soils that had never been cropped or $\mathrm{N}$ fertilized, as well as for adjacent cropped soils of the same soil series that are regularly cultivated and $\mathrm{N}$ fertilized. Although it is unknown if the mechanism of octyne inhibition may itself be temperature-dependent, the temperature niche separation determined with the octyne method agrees with previous studies that found differences in $\mathrm{AOA}$ and $\mathrm{AOB}$ amoA gene abundances or differential labeling with ${ }^{13} \mathrm{CO}_{2}$ in response to different incubation temperatures (Avrahami et al., 2011; Wu et al., 2013; Zeng et al., 2014), and with the isolation of soil AOA that grow optimally at $35-40{ }^{\circ} \mathrm{C}$ (Tourna et al., 2011; Kim et al., 2012; Lehtovirta-Morley et al., 2014, 2016). Some of these AOA isolates were obtained at an initial cultivation of $37^{\circ} \mathrm{C}$ (Lehtovirta-Morley et al., 2011, 2016; Tourna et al., 2011); however, another isolate was initially enriched at $25^{\circ} \mathrm{C}$ (Kim et al., 2012). Virtually, all AOB isolates grow best at $\leqslant 30^{\circ} \mathrm{C}$ (Jones and Morita, 1985; Stein and Arp, 1998; Jiang and Bakken, 1999; Norton et al., 2008). Examples of the response of specific rates of activity by AOB isolates to comprehensive temperature ranges are rare in the literature (Jiang and Bakken, 1999), and the influence of initial cultivation or growth temperatures on the cultures' specific rates of activity in response to temperature are uncertain. Four AOB strains that were grown at $22^{\circ} \mathrm{C}$ had their highest rates of activity at $25-30^{\circ} \mathrm{C}$ (Jiang and Bakken, 1999), and the AOB Nitrosomonas sp. $4 \mathrm{~W} 30$ (initially isolated at $10^{\circ} \mathrm{C}$ ) had highest specific rates of activity at 20 and $32^{\circ} \mathrm{C}$ when cultivated at 5 and $25^{\circ} \mathrm{C}$, respectively (Jones and Morita, 1985). The temperature response of only a few AOA isolates has been examined, and in these cases, the response of specific growth rates, not activities, to different temperatures were measured (Jung et al., 2011; Kim et al., 2012; Lehtovirta-Morley et al., 2014, 2016). Comparing coefficients generated using growth data of isolates may not be a fair comparison with the specific rates of soil-nitrifying activity that we measured in this study. For example, when the $T_{\text {opt }}$ values for respiratory (glucose mineralization) and growth (leucine incorporation) processes were compared in a soil, the $T_{\text {opt }}$ for respiration was $>20^{\circ} \mathrm{C}$ higher than the $T_{\text {opt }}$ of growth (Birgander et al., 2013), suggesting that the thermodynamic properties of growth and respiration can differ among mixed soil populations. In this context, we showed that, although the temperature range of $\mathrm{AOB}$ activity was wide $\left(4-42^{\circ} \mathrm{C}\right)$, the ability of AOB to conduct de novo protein synthesis to replace acetylene-inactivated AMO covered a much narrower temperature range. Clearly, more comparative studies are needed with $\mathrm{AOA}$ and $\mathrm{AOB}$ isolates, taking both growth and $\mathrm{NH}_{3}$-oxidizing activity into consideration.

The SQRT model predicted significantly higher $T_{\max }$ values for AOA- and AOB-driven nitrification $(P<0.01)$. We experimentally demonstrated in Pendleton noncropped soil that both $\mathrm{AOA}$ and $\mathrm{AOB}$ ( $T_{\max }$ estimates of $44.2 \pm 0.9^{\circ} \mathrm{C}$ and $42.4 \pm 0.1^{\circ} \mathrm{C}$ ) had sufficient rates of $\mathrm{NH}_{4}^{+}$turnover at $42^{\circ} \mathrm{C}$ for their respective AMO to be irreversibly inactivated by acetylene, resulting in no residual activity upon subsequent incubation at their respective $T_{\text {opt }}$ values. We also found that their heat tolerance was very similar, with AOB withstanding temperatures $\leqslant 44^{\circ} \mathrm{C}$, and AOA $\leqslant 46^{\circ} \mathrm{C}$. Perhaps it makes sense that AOA 
and $\mathrm{AOB}$ in the same soil should have similar thermal stability. Previous studies have shown that changes in the temperature response of soil microbes, using ${ }^{14} \mathrm{C}$ leucine incorporation occurred as a result of 1-2-month incubations of soil at elevated temperatures (Barcenas-Moreno et al., 2009; Birgander et al., 2013). As a result, the highest temperature in an environment, even transiently over seasons, can select for organisms that have similar heat tolerance (van Gestel et al., 2013; Schipper et al., 2014). With the acetylene inactivation approach, we confirmed the model predictions of a significantly lower $T_{\min }$ value for AOB than AOA. Through this approach, we also obtained evidence that raising the soil temperature to $10^{\circ} \mathrm{C}$ resulted in appearance of some activity of AOA AMO, but not all of it, suggesting the existence in the AOA population of different temperature responsive forms of AMO. This result contrasts with the lack of evidence for different temperature responsive forms of AMO among the AOB. With regard to model parameters, these results could suggest different interpretations of the $T_{\mathrm{s} \_ \text {max }}$ parameter for $\mathrm{AOA}$ and AOB. Because the AOB demonstrated a single temperature response, $T_{\text {s_max }}$ could indicate a purely thermodynamic response of $\mathrm{NH}_{3}$-oxidizing activity to temperature increase, whereas the higher $T_{s_{\_} \max }$ for AOA could be due to recruitment of additional AMO types within the AOA population with different thermodynamic response profiles.

Although the $\Delta C_{P}^{+}$parameter modeled from the MMRT model should be considered as an integration of multiple biochemical reactions that define nitrification, it is intriguing to consider $\Delta C_{P}^{+}$in context with specific properties of AMO. For example, Hobbs et al. (2013) demonstrated through sitedirected mutagenesis studies with the enzyme

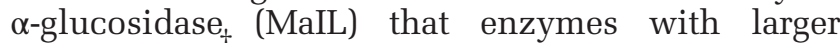
negative $\Delta C_{P}^{\ddagger}$ values have more conformational states than enzymes possessing less negative $\Delta C_{P}^{f}$ values. The soil AOB in our study expressed larger negative $\Delta C_{P}^{f}$ values than AOA $(P<0.01)$, suggesting a conformationally more flexible AOB AMO, which according to the model should be less restrained at its active site. This 'flexibility' might correspond with the broad substrate range of AMO of AOB (Hyman et al., 1988), and correlate with $T_{\text {opt }}$ and $T_{\text {s_max }}$ values that were consistently lower than the corresponding values ascribed to their soil AOA counterparts. By comparison, a less negative $\Delta C_{P}^{+}$for AOA might extrapolate to a more rigid and constrained version of AMO that may correspond with a more limited substrate range as shown by Taylor et al. (2015). This property might also explain the inability of acetylene to inactivate a fraction of AOA AMO at lower temperatures. It is well documented, albeit for unknown reasons, that the efficacy of acetylene as a substrate for both alkene and aromatic monooxygenases varies considerably (Hyman et al., 1988; Ensign et al., 1992; Yeager et al., 1999; Taylor et al., 2010a). With a less negative $\Delta C_{P}^{\ddagger}$, optimal AOA activity could be constrained to higher soil temperatures, closer to $T_{\max }$, resulting in a much narrower $T_{\text {max-opt }}$ than the AOB $(6 \pm 3$ and $15 \pm 2$ for AOA and AOB, respectively), and a significantly steeper decline (' $b$ ' parameter) in AOA-dependent activity above $T_{\text {opt }}(P<0.01)$. The significant difference in $\Delta C_{P}^{+}$for AOA and AOB might also provide support for the idea that the two groups of $\mathrm{NH}_{3}$ oxidizers utilize different biochemical mechanisms for $\mathrm{NH}_{3}$ oxidation to $\mathrm{NO}_{2}^{-}$(Walker et al., 2010; MartensHabbena et al., 2015; Kozlowski et al., 2016).

It is of some importance to consider how the $\Delta C_{P}^{\ddagger}$ values we have determined in this study fit into context with other data on temperature dependence of soil processes. The $\Delta C_{P}^{\ddagger}$ values of soil $\mathrm{AOB}$ in this study $\left(-9.3 \pm 2.5 \mathrm{~kJ} \mathrm{~mol}^{-1} \mathrm{~K}^{-1}\right)$ fell within the same range as $\Delta C_{P}^{\ddagger}$ values determined from a study of soil nitrification evaluated between 5 and $20^{\circ} \mathrm{C}\left(-10.1 \pm 2.9 \mathrm{~kJ} \mathrm{~mol}^{-1} \mathrm{~K}^{-1}\right.$; Russell et al., 2002 ; Schipper et al., 2014). In our study, $\mathrm{NO}_{2}^{-}+\mathrm{NO}_{3}^{-}$ production activity over this $^{+}$temperature range was dominated by AOB. $\Delta C_{P}^{\ddagger}$ values were also modeled from a study on temperature dependency of soil methane oxidation and values obtained were also very similar to that of AOB-driven soil nitrification $\left(-7.3 \pm 4.7 \mathrm{~kJ} \mathrm{~mol}^{-1} \mathrm{~K}^{-1}\right.$; Schipper et al., 2014). It is well known that AMO of AOB is genetically similar to particulate methane monooxygenase, and that both enzymes are capable of oxidizing both substrates (Holmes et al., 1995; Semrau et al., 1995; Arp and Stein, 2003), whereas we do not know if $\mathrm{CH}_{4}$ is a substrate for AOA AMO. It remains to be seen if $\Delta C_{P}^{\ddagger}$ values of soil nitrification from other soil environments will yield confirmatory results, and how $\Delta C_{P}^{+}$values based on rates of activity of $\mathrm{NH}_{3}$-oxidizing isolates will add to our understanding of the biochemical mechanisms behind this process and how they respond to temperature change.

\section{Value of application of SQRT and MMRT models to environmental data}

By modeling the rates of $\mathrm{NO}_{2}^{-}+\mathrm{NO}_{3}^{-}$production activity by $\mathrm{AOA}$ and $\mathrm{AOB}$ in soil, we obtained parameters that reflect the response of the AOA and AOB actively contributing to nitrification, and not just the response of the few that can be isolated into culture. This approach allowed us to determine that key characteristics $\left(T_{\min }, T_{\max }, T_{\mathrm{opt}}, T_{\mathrm{s}_{\_} \max }\right.$ and $\Delta C_{P}^{+}$) within each of the two groups of $\mathrm{NH}_{3}$ oxidizers were consistent across the study sites, and are perhaps intrinsic attributes of these groups. The modeled and experimental results yielded a clear trend for differences in $T_{\min }, T_{\mathrm{opt}}, T_{\mathrm{s} \text { max }}$ and $\Delta C_{P}^{+}$of soil $\mathrm{AOA}$ and $\mathrm{AOB}$ activities, implying fundamental differences in temperature-influenced properties of nitrification driven by the two groups of $\mathrm{NH}_{3}$ oxidizers. These thermodynamic parameters could be utilized in trait-based modeling systems to gain understanding into how past 
climates have shaped the current communities of $\mathrm{NH}_{3}$ oxidizers, and predict future response to climate change.

\section{Conflict of Interest}

The authors declare no conflict of interest.

\section{Acknowledgements}

We thank J Rouske, L Schipper, V Arcus and M Dolan for assistance with modeling, and faculty and staff at the Agricultural Experiment Stations with soil collection. We also thank the anonymous reviewers for critical comments which lead to a stronger paper. This research was supported by USDA NIFA award 2012-67019-3028, and an Oregon Agricultural Research Foundation competitive grant.

\section{References}

Adair KL, Schwartz E. (2008). Evidence that ammoniaoxidizing archaea are more abundant than ammoniaoxidizing bacteria in semiarid soils of northern Arizona, USA. Microbial Ecol 56: 420-426.

Alves RJ, Wanek W, Zappe A, Richter A, Svenning MM, Schleper C et al. (2013). Nitrification rates in Arctic soils are associated with functionally distinct populations of ammonia-oxidizing archaea. ISME J 7: 1620-1631.

Arp DJ, Stein LY. (2003). Metabolism of inorganic N compounds by ammonia-oxidizing bacteria. Crit Rev Biochem Mol Biol 38: 471-495.

Avrahami S, Liesack W, Conrad R. (2003). Effects of temperature and fertilizer on activity and community structure of soil ammonia oxidizers. Environ Microbiol 5: 691-705.

Avrahami S, Jia ZJ, Neufeld JD, Murrell JC, Conrad R, Kusel K. (2011). Active autotrophic ammoniaoxidizing bacteria in biofilm enrichments from simulated creek ecosystems at two ammonium concentrations respond to temperature manipulation. Appl Environ Microbiol 77: 7329-7338.

Barcenas-Moreno G, Gomez-Brandon M, Rousk J, Baath E. (2009). Adaptation of soil microbial communities to temperature: comparison of fungi and bacteria in a laboratory experiment. Global Change Biol 15: 2950-2957.

Birgander J, Reischke S, Jones DL, Rousk J. (2013). Temperature adaptation of bacterial growth and ${ }^{14} \mathrm{C}$-glucose mineralisation in a laboratory study. Soil Biol Biochem 65: 294-303.

Bouskill NJ, Tang J, Riley WJ, Brodie EL. (2012). Traitbased representation of biological nitrfication: model development testing, and predicted community composition. Front Microbiol 3: 364.

Cookson WR, Cornforth IS, Rowarth JS. (2002). Winter soil temperature (2-15 degrees C) effects on nitrogen transformations in clover green manure amended or unamended soils; a laboratory and field study. Soil Biol Biochem 34: 1401-1415.

Daims H, Lebedeva EV, Pjevac P, Han P, Herbold C, Albertsen $\mathrm{M}$ et al. (2015). Complete nitrification by Nitrospira bacteria. Nature 528: 504-509.
Dalias P, Anderson JM, Bottner P, Couteaux MM. (2002). Temperature responses of net nitrogen mineralization and nitrification in conifer forest soils incubated under standard laboratory conditions. Soil Biol Biochem 34: 691-701.

de la Torre JR, Walker CB, Ingalls AE, Konneke M, Stahl DA. (2008). Cultivation of a thermophilic ammonia oxidizing archaeon synthesizing crenarchaeol. Environ Microbiol 10: 810-818.

Ensign SA, Hyman MR, Arp DJ. (1992). Cometabolic degradation of chlorinated alkenes by alkene monooxygenase in a propylene-grown Xanthobacter strain. Appl Environ Microbiol 59: 3038-3046.

Fierer N, Schimel JP, Holden PA. (2003). Influence of drying-rewetting frequency on soil bacterial community structure. Microb Ecol 45: 63-71.

Giguere AT, Taylor AE, Myrold DD, Bottomley PJ. (2015). Nitrification responses of soil ammonia-oxidizing archaea and bacteria to ammonium concentrations. Soil Sci Soc Am J 79: 1366-1374.

Hatzenpichler R, Lebedeva EV, Spieck E, Stoecker K, Richter A, Daims $\mathrm{H}$ et al. (2008). A moderately thermophilic ammonia-oxidizing crenarchaeote from a hot spring. Proc Natl Acad Sci USA 105: 2134-2139.

Hatzenpichler R. (2012). Diversity, physiology, and niche differentiation of ammonia-oxidizing archaea. Appl Environ Microbiol 78: 7501-7510.

Hobbs JK, Jiao WT, Easter AD, Parker EJ, Schipper LA, Arcus VL. (2013). Change in heat capacity for enzyme catalysis determines temperature dependence of enzyme catalyzed rates. ACS Chem Biol 8: 2388-2393.

Holmes AJ, Costello A, Lidstrom ME, Murrell JC. (1995). Evidence that particulate methane monooxygenase and ammonia monooxygenase may be evolutionarily related. FEMS Microbiol Lett 132: 203-208.

Hu HW, Zhang LM, Yuan CL, Zheng Y, Wang JT, Chen DL et al. (2015). The large-scale distribution of ammonia oxidizers in paddy soils is driven by soil $\mathrm{pH}$, geographic distance, and climatic factors. Front Microbiol 4: 938.

Hyman MR, Wood PM. (1985). Suicidal inactivation and labeling of ammonia monooxygenase by acetylene. Biochem J 227: 719-725.

Hyman MR, Murton IB, Arp DJ. (1988). Interaction of ammonia monooxygenase from Nitrosomonas europaea with alkanes, alkenes, and alkynes. Appl Environ Microbiol 54: 3187-3190.

Jiang QQ, Bakken LR. (1999). Comparison of Nitrosospira strains isolated from terrestrial environments. FEMS Microbiol Ecol 30: 171-186.

Jones RD, Morita RY. (1985). Low-temperature growth and whole-cell kinetics of a marine ammonium oxidizer. Mar Ecol Prog Ser 21: 239-243.

Jones RD, Morita RY, Koops HP, Watson SW. (1988). A new marine ammonium-oxidizing bacterium, Nitrosomonas cryotolerans Sp-Nov. Canadian J Microbiol 34: 1122-1128.

Jung MY, Park SJ, Min D, Kim JS, Rijpstra WI, Sinninghe Damste JS et al. (2011). Enrichment and characterization of an autotrophic ammonia-oxidizing archaeon of mesophilic crenarchaeal group I.1a from an agricultural soil. Appl Environ Microbiol 77: 8635-8647.

Kim JG, Jung MY, Park SJ, Rijpstra WIC, Damste JSS, Madsen EL et al. (2012). Cultivation of a highly enriched ammonia-oxidizing archaeon of thaumarchaeotal group 
I.1b from an agricultural soil. Environ Microbiol 14: 1528-1543

Kozlowski JA, Stieglmeier M, Schleper C, Klotz MG, Stein LY. (2016). Pathways and key intermediates required for obligate aerobic ammonia-dependent chemolithotrophy in bacteria and Thaumarchaeota. ISME J 10: 1836-1845.

Lehtovirta-Morley LE, Stoecker K, Vilcinskas A, Prosser JI, Nicol GW. (2011). Cultivation of an obligate acidophilic ammonia oxidizer from a nitrifying acid soil. Proc Natl Acad Sci USA 108: 15892-15897.

Lehtovirta-Morley LE, Ge CR, Ross J, Yao HY, Nicol GW, Prosser JI. (2014). Characterisation of terrestrial acidophilic archaeal ammonia oxidisers and their inhibition and stimulation by organic compounds. FEMS Microbiol Ecol 89: 542-552.

Lehtovirta-Morley LE, Ross J, Hink L, Weber EB, GubryRangin C, Thion C et al. (2016). Isolation of 'Candidatus Nitrosocosmicus franklandus', a novel ureolytic soil archaeal ammonia oxidiser with tolerance to high ammonia concentration. FEMS Microbiol Ecol. 92: fiw057.

Leininger S, Urich T, Schloter M, Schwark L, Qi J, Nicol GW et al. (2006). Archaea predominate among ammoniaoxidizing prokaryotes in soils. Nature 442: 806-809.

Liu SS, Wang F, Xue K, Sun B, Zhang YG, He ZL et al. (2015). The interactive effects of soil transplant into colder regions and cropping on soil microbiology and biogeochemistry. Environ Microbiol 17: 566-576.

Malhi SS, McGill WB. (1982). Nitrification in three Alberta soils - Effect of temperature, moisture and substrate concentration. Soil Biol Biochem 14: 393-399.

Martens-Habbena W, Qin W, Horak REA, Urakawa H, Schauer AJ, Moffett JW et al. (2015). The production of nitric oxide by marine ammonia-oxidizing archaea and inhibition of archaeal ammonia oxidation by a nitric oxide scavenger. Environ Microbiol 17: 2261-2274.

Myers RJK. (1975). Temperature effects on ammonification and nitrification in a tropical soil. Soil Biol Biochem 7: 83-86.

Norton JM, Klotz MG, Stein LY, Arp DJ, Bottomley PJ, Chain PS et al. (2008). Complete genome sequence of Nitrosospira multiformis, an ammonia-oxidizing bacterium from the soil environment. Appl Environ Microbiol 74: 3559-3572.

Offre P, Prosser JI, Nicol GW. (2009). Growth of ammoniaoxidizing archaea in soil microcosms is inhibited by acetylene. FEMS Microbiol Ecol 70: 99-108.

Prosser JI, Nicol GW. (2012). Archaeal and bacterial ammonia-oxidisers in soil: the quest for niche specialisation and differentiation. Trends Microbiol 20: $523-531$.

Ratkowsky DA, Lowry RK, McMeekin TA, Stokes AN, Chandler RE. (1983). Model for bacterial culture growth rate throughout the entire biokinetic temperature range. J Bacteriol 154: 1222-1226.

Russell CA, Fillery IRP, Bootsma N, McInnes KJ. (2002). Effect of temperature and nitrogen source on nitrification in a sandy soil. Commun Soil Sci Plant Anal 33: 1975-1989.

Schauss K, Focks A, Leininger S, Kotzerke A, Heuer H, Thiele-Bruhn S et al. (2009). Dynamics and functional relevance of ammonia-oxidizing archaea in two agricultural soils. Environ Microbiol 11: 446-456.

Schipper LA, Hobbs JK, Rutledge S, Arcus VL. (2014). Thermodynamic theory explains the temperature optima of soil microbial processes and high Q(10) values at low temperatures. Global Change Biol 20: 3578-3586.

Schleper C. (2010). Ammonia oxidation: different niches for bacteria and archaea? ISME J 4: 1092-1094.

Semrau JD, Chistoserdov A, Lebron J, Costello A, Davagnino J, Kenna E et al. (1995). Particulate methane monooxygenase genes in methanotrophs. J Bacteriol 177: 3071-3079.

Stark JM. (1996). Modeling the temperature response of nitrification. Biogeochem 35: 433-445.

Stark JM, Firestone MK. (1996). Kinetic characteristics of ammonium-oxidizer communities in a California oak woodland-annual grassland. Soil Biol Biochem 28: 1307-1317.

Stein LY, Arp DJ. (1998). Ammonium limitation results in the loss of ammonia-oxidizing activity in Nitrosomonas europaea. Appl Environ Microbiol 64: 1514-1521.

Sun RB, Guo XS, Wang DZ, Chu HY. (2015). Effects of longterm application of chemical and organic fertilizers on the abundance of microbial communities involved in the nitrogen cycle. Appl Soil Ecol 95: 171-178.

Taylor A, Arp D, Bottomley P, Semprini L. (2010a). Extending the alkene substrate range of vinyl chloride utilizing Nocardioides sp. strain JS614 with ethene oxide. Appl Microbiol Biotechnol 87: 2293-2302.

Taylor AE, Zeglin LH, Dooley S, Myrold DD, Bottomley PJ. (2010b). Evidence for different contributions of archaea and bacteria to the ammonia-oxidizing potential of diverse Oregon soils. Appl Environ Microbiol 76: 7691-7698.

Taylor AE, Zeglin L, Wanzek TA, Myrold DD, Bottomley PJ. (2012). Dynamics of ammonia oxidizing archaea and bacteria populations and contributions to soil nitrification potentials. ISME J 6: 2024-2032.

Taylor AE, Vajrala N, Giguere AT, Gitelman AI, Arp DJ, Myrold DD et al. (2013). Use of aliphatic n-alkynes to discriminate soil nitrification activities of ammoniaoxidizing Thaumarchaea and Bacteria. Appl Environ Microb 79: 6544-6551.

Taylor AE, Taylor K, Tennigkeit B, Palatinszky M, Stieglmeier M, Myrold DD et al. (2015). Inhibitory effects of $\mathrm{C}_{2}$ to $\mathrm{C}_{10}$ 1-alkynes on ammonia oxidation in two Nitrososphaera species. Appl Environ Microbiol 81: 1942-1948.

Tourna M, Freitag TE, Nicol GW, Prosser JI. (2008). Growth, activity and temperature responses of ammonia-oxidizing archaea and bacteria in soil microcosms. Environ Microbiol 10: 1357-1364.

Tourna M, Stieglmeier M, Spang A, Konneke M, Schintlmeister A, Urich $\mathrm{T}$ et al. (2011). Nitrososphaera viennensis, an ammonia oxidizing archaeon from soil. Proc Natl Acad Sci USA 108: 8420-8425.

Vajrala N, Bottomley PJ, Stahl DA, Arp DJ, Sayavedra-Soto LA. (2014). Cycloheximide prevents the de novo polypeptide synthesis required to recover from acetylene inhibition in Nitrosopumilus maritimus. FEMS Microbiol Ecol 88: 495-502.

van Gestel NC, Reischke S, Bååth E. (2013). Temperature sensitivity of bacterial growth in a hot desert soil with large temperature fluctuations. Soil Biol Biochem 65: 180-185.

van Kessel MAHJ, Speth DR, Albertsen M, Nielsen PH, Op den Camp HJM, Kartal B et al. (2015). Complete nitrification by a single microorganism. Nature 528: $555-559$.

Walker CB, de la Torre JR, Klotz MG, Urakawa H, Pinel N, Arp DJ et al. (2010). Nitrosopumilus maritimus genome 
908

reveals unique mechanisms for nitrification and autotrophy in globally distributed marine crenarchaea. Proc Natl Acad Sci USA 107: 8818-8823.

Wu YC, Ke XB, Hernandez M, Wang BZ, Dumont MG, Jia ZJ et al. (2013). Autotrophic growth of bacterial and archaeal ammonia oxidizers in freshwater sediment microcosms incubated at different temperatures. Appl Environ Microbiol 79: 3076-3084.
Yeager CM, Bottomley PJ, Arp DJ, Hyman MR. (1999). Inactivation of toluene 2-monooxygenase in Burkholderia cepacia G4 by alkynes. Appl Environ Microbiol 65: 632-639.

Zeng J, Zhao DY, Yu ZB, Huang R, Wu QLL. (2014). Temperature responses of ammonia-oxidizing prokaryotes in freshwater sediment microcosms. PloS One $\mathbf{9}$ : e100653.

Supplementary Information accompanies this paper on The ISME Journal website (http://www.nature.com/ismej) 